\title{
A Relationship Between Avian Foraging Behavior and Infestation by Trombiculid Larvae (Acari) in Chiapas, Mexico
}

\author{
Thomas V. Dietsch ${ }^{1}$ \\ School of Natural Resources and Environment, University of Michigan, Ann Arbor, Michigan 48109, U.S.A.
}

\begin{abstract}
Birds face varying risk from parasites as they select and utilize habitat. Unfortunately, behavioral and habitat correlates of parasitism in birds are not well documented. This study combines data from a foraging behavior study with results from a banding study to test whether behavior and habitat affect an ectoparasite infestation by trombiculid mite (chigger) larvae on the bird community found in two different coffee agroecosystems in Chiapas, Mexico. Individuals from bird species with regular prevalence (i.e., infestation) foraged more frequently in lower vegetative layers and had significantly lower foraging height than those from species with little or no prevalence, suggesting that foraging near the ground increases exposure risk to chigger larvae. Using linear regression, across species, parasite prevalence decreased with increasing average foraging height. Lower infestation rates were found in coffee agroecosystems with higher management intensity (i.e., less shade and drier conditions), suggesting that management activities influence infestation rates. Consequently, drier tropical habitats may pose less risk to birds from ectoparasites, though seasonal prevalence was highest during the winter dry season. Although no direct link was found between host condition and infestation by chigger larvae on the wintering grounds, birds were sampled during the middle of the over-wintering period, not the end when infestation could affect birds fattening for migration.
\end{abstract}

Abstract in Spanish is available at http://www.blackwell-synergy.com/loi/btp.

Key words: avian host behavior; coffee agroecosystems; habitat quality and use; host-parasite interactions; Trombiculidae.

MORE THAN 2500 SPECIES OF MITES (ACARI) FROM 40 FAMILIES ARE known to parasitize birds (Proctor \& Owens 2000). Though many species are host-specific, there are a number of generalist species, including many chigger mite species (Trombiculidae), which are widespread and may present potentially grave consequences for birds. Unfortunately, little is known about the distribution and frequency of ectoparasite infestation among bird species, especially in the tropics. Parasitism is also a poorly understood challenge faced by long-distance migratory birds that over-winter in tropical habitats. Energetic costs of endo- and ectoparasites may reduce survival during migration and leave birds that arrive on the breeding grounds in poor condition. In addition, mites capable of attaching to multiple hosts can transmit blood-borne diseases.

Much of the work on ectoparasites has focused on nest and feather mites. Although evidence of direct harm is equivocal, feather mites can damage feathers and induce depluming with potential adverse consequences in mate selection (Proctor \& Owen 2000). Depluming could also have important consequences for flight and thermoregulation, which would have direct impacts on survivorship (Booth et al. 1993). Nest mites have been implicated in transmitting disease, can induce paralysis, and reduce fecundity and nestling growth rates (Proctor \& Owen 2000). Although nests may provide a more dependable location where parasites can locate hosts, ectoparasites with free-living life stages are able to locate and attach themselves to hosts in a wide range of habitats (Baker et al. 1956).

The Trombiculidae, ectoparasitic chigger mites, are implicated in at least one major tropical human disease, scrub typhus (Orientia

Received 31 October 2006; revision accepted 8 July 2007.

${ }^{1}$ Current address: Center for Tropical Research, UCLA Institute of the Environment, Box 951496, Los Angeles, California 90095-1496, U.S.A. tsutsugamushi Ogata, formerly in the genus Rickettsia), and a number of wildlife diseases (Ewing 1944, Wharton \& Fuller 1952, Baker et al. 1956, Proctor \& Owens 2000). Chiggers are parasitic only in their larval stages, whereas in the successive nymphal and adult stages, they are free living and predominantly predatory on the eggs and young instars of small arthropods (Baker et al. 1956). Freeliving adults lay eggs away from the host. After hatching, chiggerlarvae locate a host and then attach themselves, feeding on the host through a proboscis inserted through the skin. Chigger-larvae typically remain attached to their hosts for 3-4 d; however, this is species dependent and some species can remain attached for as long as $30 \mathrm{~d}$ (Wharton \& Fuller 1952, Clayton \& Walther 1997). The host frequently suffers from dermatitis near the site of attachment, as is well known when these larvae are incidental parasites of humans. Members of this family are globally distributed and are known to affect a wide range of potential hosts, but little is known about their ecology. In particular, factors that contribute to infestation risk are not well understood or whether there are significant physiological costs to individual birds infested with this ectoparasite.

Chiggers are usually associated with the soil, which may make birds that forage on or spend time near the ground more susceptible. Literak et al. (2001) noted that birds with a high prevalence of trombiculid larvae were members of ground or near-ground foraging guilds. They hypothesized that prevalence rates for individual species depend on the length of individual exposure in the environment with chigger larvae. Similarly, Pruett-Jones and PruettJones (1991) observed that members of low foraging guilds also had higher prevalences of ticks. However, the relationship that species with higher prevalence forage closer to the ground has not been directly tested.

In Chiapas, Mexico, ectoparasitic chiggers infest a wide range of resident and migratory species and many species have a high 
prevalence of infestation. Mean abundance and mean intensity of infestation were reported for 97 species captured and inspected during the course of this study (see Tables 2 and 3 in Dietsch 2005a). In this region, chigger larvae are relatively common on birds and their abundance varies seasonally (Dietsch 2005a). In general, prevalence was higher for resident than migratory species, but prevalence was unexpectedly high on some long-distance migrants, as high as 0.73 for Swainson's Thrush, a value on par with heavily infested resident species (Dietsch 2005a).

In this study, I test the hypothesis that there is a relationship between where birds forage and their risk of infestation by trombiculid larvae using foraging height and mite prevalence data from two previous studies (Dietsch 2005a, Dietsch et al. 2007). Using prevalence as a measure of infestation, I test in particular whether regularly infested (susceptible) species forage at lower heights than nonsusceptible species. I also use coffee plantations under different shade management practices as a natural experiment to compare infestation rates across habitats by season and year for Neotropical resident and Nearctic migratory birds. Finally, I evaluate whether infestation affects avian host body condition using size-corrected body weight as a measure of condition.

\section{METHODS}

STUDY SITE.- - I carried out the study in the Soconusco region, a major coffee growing area, in Chiapas, Mexico. The region is located in the Sierra Madre de Chiapas mountain range east of Tapachula and just north of the Guatemala border near the Pacific coast with coffee grown at elevations of 300-1500 m. Over a 2-yr period, birds were mist netted at $1000 \mathrm{~m}$ in two coffee agroecosystems of Finca Irlanda, a large coffee farm $\left(15^{\circ} 10.26^{\prime} \mathrm{N}, 92^{\circ} 20.29^{\prime} \mathrm{W}\right)$. Using the 'gestalt' system described by Moguel and Toledo (1999), both systems are classified as commercial polyculture, a coffee production system using a low-to-moderate diversity of pruned shade trees, both certified organic. Both agroecosystems use a diversity of shade trees, the most abundant being several Inga species and Alchornia latifolia (Martinez $\&$ Peters 1996). In one agroecosystem, referred to as 'Restoration,' the landowner plants additional native forest trees to produce greater canopy cover with higher species richness and tree abundance. At the time of this research, the Restoration system had sufficient canopy cover, species richness, and abundance of shade trees for the coffee produced to be certified as shade grown, although the canopy height and structural diversity had not yet met certification criteria. I refer to the unaugmented agroecosystem as Production.

BANDING AND MITE SCORES.- - Resident birds were banded as part of a study on foraging behavior and diet selection in coffee agroecosystems (Dietsch 2003). Resident birds were color banded to allow identification of previously captured or observed individuals. Tail feathers of migratory birds and resident hummingbirds were clipped to identify individuals recaptured within a season. Birds were caught using mist nets during two rainy summer seasons (19 June-14 July 2000 and 5-28 June 2001), a period of peak breeding activity for resident birds, and two dry winter seasons (9-25 January 2001 and
28 January-4 February 2002) when both residents and migrants were present. Birds were netted in two plots in each coffee agroecosystem type during summer 2000 and winter 2001, but in only one plot per agroecosystem in summer 2001 and winter 2002. For summer 2000, winter 2001, and summer 2001, the research team ran 25 nets (198 m total) for three consecutive days in each plot, and in winter 2002, we used 12 nets $(96 \mathrm{~m})$ for two consecutive days per plot. The team opened nets at dawn $(\sim 0600 \mathrm{~h})$ and closed at $1100 \mathrm{~h}$ each day. Weight, body fat score, molt, and other standard measurements were taken for each bird captured (Pyle 1997).

Each bird was checked for the highly visible red-colored chigger larvae and infestation was scored using a mite ranking protocol (Dietsch 2005b). The ranking protocol (scored from 0 to 4, with $0=$ no chiggers) was designed to provide a rapid assessment of the extent of infestation and the relative abundance of mite larvae on infested individuals. The ranking score was based roughly on a simple count of the number of locations on a bird with mite larvae or colonies (i.e., a ranking score of $1=1$ body location and score of $2=2$ body locations, etc.). The score was then adjusted by the size of larvae colonies in the location (Dietsch 2005a,b). A location refers to a single body area, such as behind one leg, behind a wing, or the lower belly (areas where chigger larvae commonly cluster). A colony is a single grouping of mite larvae. Individual larvae are visible as bumps within a grouping. There was a significant linear correlation between ranking protocol scores and actual counts of mite larvae abundance (Dietsch 2005b). Each bird caught was visually inspected while checking for body molt by blowing feathers aside to examine the skin surface. This inspection included focal areas to which mite larvae seem to attach, particularly, along feather tracts behind the legs and wings.

FORAGING BEHAVIOR.-Foraging observations were conducted in summer 2000 and winter 2001 in plots under both shade management systems. Observers rotated among plots to ensure equal effort by all observers in each area. While walking slowly through a plot, an observer noted the foraging behavior of birds using a protocol adapted from Greenberg et al. (1999). Birds were located visually and audibly to reduce bias toward conspicuous individuals or species. Observers collected data on as many individuals as possible. In mixed-species flocks, only a few individuals of each species were observed to prevent double counting. Band combinations were also noted where possible for birds observed. During analysis, only the first observation was used for individuals with multiple sightings. For each foraging maneuver observed, height of the bird, canopy height, and foraging layer (ground, herbaceous, coffee, or shade) were noted (see Dietsch et al. 2007 for complete description of foraging observation methods). Aerial maneuvers were classified by point of origin for the maneuver. The ground layer included soil, leaf litter, and woody debris. The herbaceous layer included all lowlying vegetation below the coffee layer. All noncoffee plants at or above the coffee layer were included in the shade layer.

BODY CONDITION.-A body-condition index was generated by dividing body weight by wing-chord measure to correct body weight for differences in size of the bird. Index values were not normally 
distributed for many species. I compared indices for infested and noninfested individuals of each species using the nonparametric Mann-Whitney test. Only species with more than 20 captures of different individuals were evaluated to allow for greater replication in comparisons.

STATISTICAL ANALYSES.-I use prevalence to refer to the proportion of individual hosts within a given group infested by at least one mite larva, mean abundance is the average number of mite larvae recorded across all individual hosts examined, and mean intensity is the average number of mite larvae recorded across all infested individuals (Margolis et al. 1982, Duffy 1983, Pruett-Jones \& Pruett-Jones 1991, Bush et al. 1997). The larval ranking scores provide a good estimate of the number of individual mite larvae per bird (Dietsch 2005a,b). In this study, I used these scores as an index of the actual number of mite larvae for calculating mean abundance and mean intensity. I evaluated differences in prevalence using contingency table Chi-squared tests. I evaluated differences in mean abundance and mean intensity using nonparametric statistics because values were not normally distributed. Foraging observations were compared between species of birds that were susceptible (prevalence $\geq$ $5 \%$ ) and nonsusceptible (prevalence $<5 \%$ ) to mite infestation. This subjective cutoff was selected to distinguish those species that regularly had parasites (susceptible) from those that never or rarely had parasites (nonsusceptible). The numbers of observations of birds in each layer for each group were compared using contingency table Chi-squared tests. Foraging height data were also not normally distributed so nonparametric Mann-Whitney $U$ tests were used for comparisons. I used linear regression to test for a correlation between species average foraging height and species prevalence. Only species with $>10$ foraging observations and $>10$ mite inspections were included in the regression to reduce spurious effects from low sample sizes. I determined $\mu$-values with Bonferroni correction for those analyses with multiple species (Manly 2001). I used StatView (v 5.0.1, SAS Institute, Inc.), SPSS (v11.0 for Macintosh, SPSS, Inc.) and Stata (Intercooled v8.2 for Macintosh, StataCorp, Inc.) for statistical analyses. The values reported in the Results section are means \pm SE.

\section{RESULTS}

HOST FORAGING BEHAVIOR.-Susceptible host species (bird species with prevalence $\geq 5 \%$ ) foraged more frequently in lower vegetative layers than did nonsusceptible bird species (Summer $2000\{$ S00 $\}$ : $\chi^{2}=65.5, P<0.0001, \mathrm{df}=1, N=938$; Winter $2001\{\mathrm{~W} 01\}$ : $\chi^{2}=82.5, P<0.0001, \mathrm{df}=1, N=1053$; Fig. 1). In addition, the difference in the proportion of foraging observations in lower strata between susceptible and nonsusceptible species was greater during the winter when prevalence is highest $(25.1 \%$ in winter and $20.6 \%$ in summer; Fig. 1). Similarly, susceptible host species foraged lower than nonsusceptible (respective means: $4.9( \pm 0.2)$ $\mathrm{m}$ and $7.2( \pm 0.1) \mathrm{m}$, Mann-Whitney $U$ test, $P<0.0001, N=$ 1987). For these foraging observations, canopy height did not differ significantly (susceptible: $12.2( \pm 0.15) \mathrm{m}$; nonsusceptible: 12.5

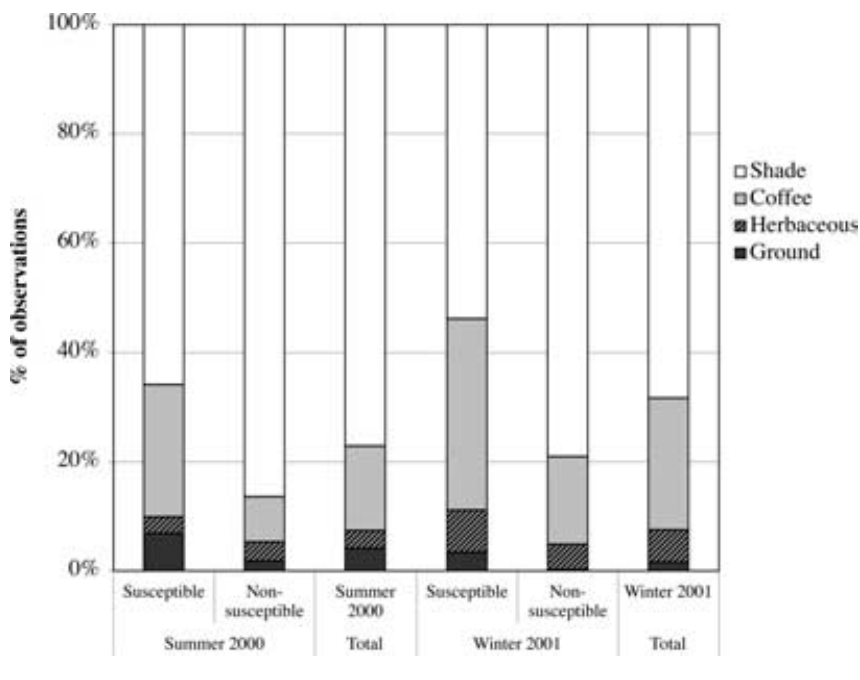

FIGURE 1. Proportion of foraging observations in each vegetation layer by season for bird species susceptible ( $>5 \%$ prevalence) and nonsusceptible to chigger mites. Within each season, susceptible species foraged more frequently in the lower vegetative strata (coffee, herbaceous, and ground layers). In addition, the difference in the proportion of foraging observations in lower strata between susceptible and nonsusceptible species was greater during the winter when prevalence is highest $(25.1 \%$ in winter and $20.6 \%$ in summer).

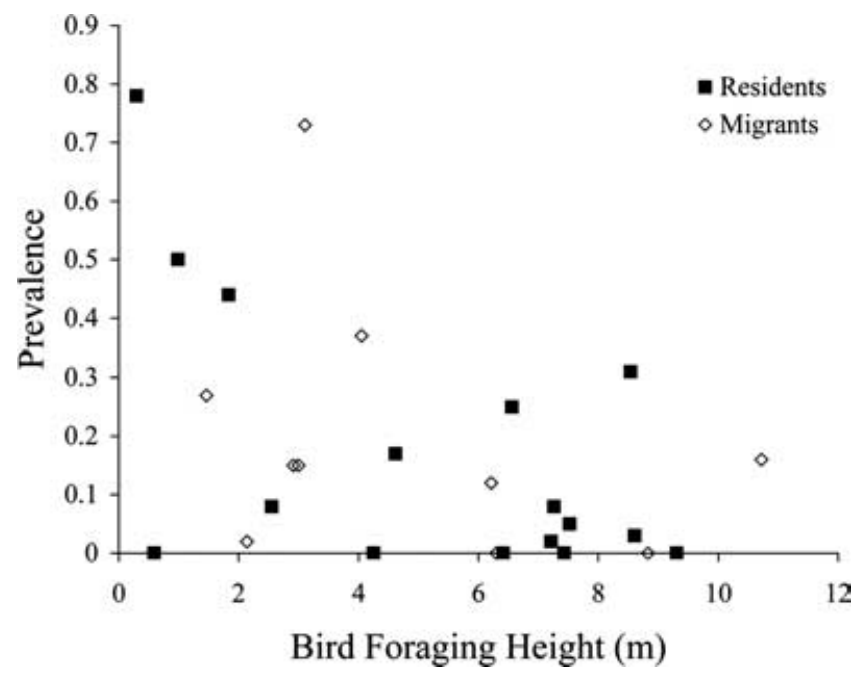

FIGURE 2. Average foraging height $(\mathrm{m})$ and prevalence for each resident and migratory bird species with over 20 observations.

$( \pm 0.13) \mathrm{m}$, Mann-Whitney $U$ test, $P=0.09, N=1981)$. In addition, using linear regression by host species, parasite prevalence decreased with increasing average foraging height (Fig. 2; Prevalence (as a proportion) $=0.36-0.036 \times$ Mean Foraging Height $(\mathrm{m})$, $\left.R^{2}=0.24, F=7.36, P=0.012, \mathrm{df}=1,24\right)$.

During the dry winter months, when infestation prevalence was higher for resident species than migrants (Dietsch 2005a), overall, birds foraged more frequently in lower layers $\left(\chi^{2}=27.7, P<\right.$ $0.0001, \mathrm{df}=1, N=1326$; Fig. 1 ). Similarly, comparing across 
seasons, residents foraged lower during summer, also when prevalence was higher, but the difference was not strongly significant (S00: $5.8( \pm 0.2) \mathrm{m}$; W01: $6.4( \pm 0.3) \mathrm{m}$, Mann-Whitney $U$ test, $P=0.12, N=1318$ ). Due to tree growth during the rainy summer season, the canopy height was also significantly higher during the winter season (S00: $12.1( \pm 0.2) \mathrm{m}$; W01: $12.8( \pm 0.2) \mathrm{m}$, Mann-Whitney $U$ test, $P<0.0001$, $\mathrm{df}=1, N=1312)$. Within each season, susceptible resident species foraged lower than nonsusceptible residents (S00: susceptible $4.7( \pm 0.2) \mathrm{m}$, nonsusceptible $6.7( \pm 0.2) \mathrm{m}, N=936$; W01: susceptible $5.5( \pm 0.4) \mathrm{m}$, nonsusceptible $7.4( \pm 0.4) \mathrm{m}$, $N=382$; both Mann-Whitney $U$ tests, $P<0.0001$ ). During winter, susceptible migrants also foraged significantly lower than nonsusceptible migrants (susceptible $4.6( \pm 0.3) \mathrm{m}$, nonsusceptible $7.7( \pm 0.2) \mathrm{m}$; Mann-Whitney $U$ test, $P<0.0001, N=$ 668). Evaluating susceptible and nonsusceptible species separately, foraging heights did not differ significantly between seasons for susceptible, but differed significantly for nonsusceptible (susceptible: S00 $4.8( \pm 0.2) \mathrm{m}$, W01 $5.0( \pm 0.2) \mathrm{m}$; Mann-Whitney $U$ test, $P=0.89, N=871$; nonsusceptible: S00 $6.8( \pm 0.2) \mathrm{m}$, W01 7.6 $( \pm 0.2) \mathrm{m}$, Mann-Whitney $U$ test, $P=0.0002, N=1116)$.

MANAGEMENT SYSTEMS. - For all captures, birds in the less-intensive commercial polyculture shade management system (Restoration) had a higher prevalence of mite infestation than the more open Production system (Restoration: $18.4 \%$, Production: $8.4 \% ; \chi^{2}=35.8$, $P<0.0001, \mathrm{df}=1)$. This difference was also significant for susceptible species (Restoration: $34.2 \%$, Production: $20.8 \% ; \chi^{2}=16.0$, $P<0.0001, \mathrm{df}=1$; Fig. 3). Prevalence was consistently higher in Restoration than Production for susceptible residents and migrants across seasons (Fig. 3). Foraging height was lower in Production than Restoration $(5.1( \pm 0.1) \mathrm{m}$ and $7.1( \pm 0.2) \mathrm{m}$, respectively; MannWhitney $U$ test, $P<0.0001, N=1978)$. Susceptible species also

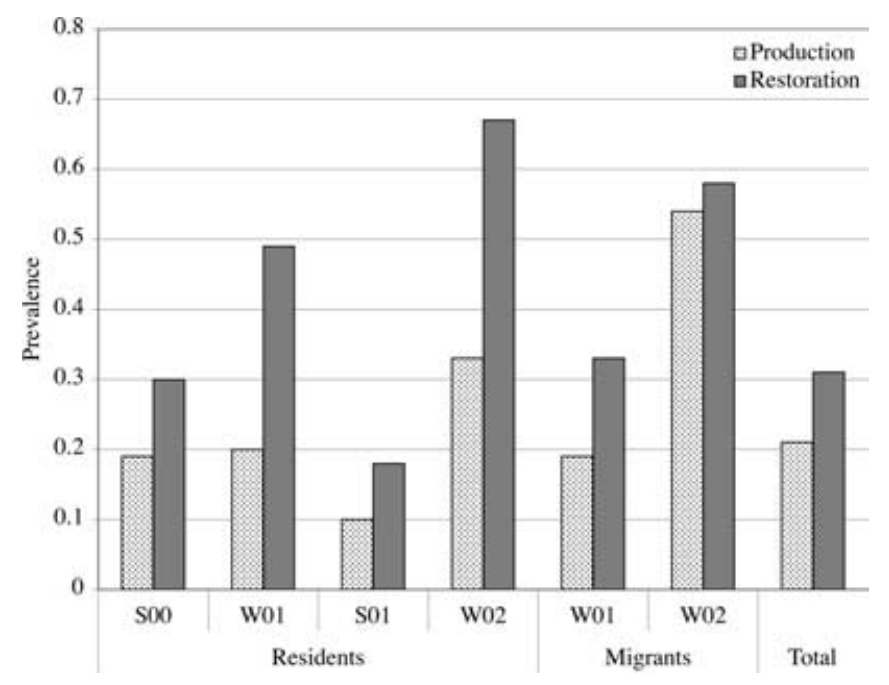

FIGURE 3. Prevalence of chigger larvae infestation for combined susceptible resident and migratory bird species by coffee agroecosystem and season. Production used more-intensive management practices than Restoration.
TABLE 1. Prevalence, mean abundance, and mean intensity of chigger mites for bird species with more than ten captures in each management system (Production and Restoration) in Chiapas, Mexico. Differences are shown between management systems (Contingency Table $\chi^{2}$ for prevalence and Mann-Whitney $U$ test $(M W)$ for mean abundance and mean intensity).

\begin{tabular}{lccc}
\hline Prevalence & Production & Restoration & Difference \\
\hline Turdus grayi & 0.07 & 0.23 & $0.16, \chi^{2}=6.1, P=0.013$ \\
Troglodytes aedon & 0.52 & 0.35 & $0.17, \chi^{2}=1.5, P=0.23$ \\
Basileuterus rufifrons & 0.08 & 0.15 & $0.07, \chi^{2}=1.2, P=0.28$ \\
Piranga leucoptera & 0.14 & 0.00 & $0.14, \chi^{2}=1.6, P=0.21$ \\
Catharus ustulatus & 0.59 & 0.77 & $0.18, \chi^{2}=2.6, P=0.11$ \\
Wilsonia pusilla & 0.11 & 0.22 & $0.11, \chi^{2}=1.1, P=0.29$ \\
\hline Mean Abundance & & & \\
\hline Turdus grayi & 0.07 & 0.34 & $0.278, \mathrm{MW}, P=0.10$ \\
Troglodytes aedon & 1.00 & 0.57 & $0.435, \mathrm{MW}, P=0.24$ \\
Basileuterus rufifrons & 0.10 & 0.15 & $0.055, \mathrm{MW}, P=0.58$ \\
Piranga leucoptera & 0.14 & 0.00 & $0.143, \mathrm{MW}, P=0.56$ \\
Catharus ustulatus & 1.14 & 1.87 & $0.734, \mathrm{MW}, P=0.026$ \\
Wilsonia pusilla & 0.14 & 0.22 & $0.079, \mathrm{MW}, P=0.54$ \\
\hline Mean Intensity & & & \\
\hline $\begin{array}{l}\text { Turdus grayi } \\
\text { Troglodytes aedon }\end{array}$ & 1.00 & 1.52 & $0.529, \mathrm{MW}, P=0.15$ \\
Basileuterus rufifrons & 1.25 & 1.63 & $0.304, \mathrm{MW}, P=0.63$ \\
Piranga leucoptera & 1.00 & & $0.25, \mathrm{MW}, P=0.54$ \\
Catharus ustulatus & 1.94 & 2.43 & $0.492, \mathrm{MW}, P=0.09$ \\
Wilsonia pusilla & 1.33 & 1.00 & $0.333, \mathrm{MW}, P=0.48$ \\
\hline & & & \\
\hline & & & \\
\hline
\end{tabular}

foraged more frequently in lower vegetation layers in Production than Restoration (Production: $N=405$, shade 53.3\%, lower layers 46.7\%; Restoration: $N=469$, shade $64.6 \%$, lower layers $35.4 \%$; $\left.\chi^{2}=11.5, P=0.001\right)$. Within each management system, foraging height for susceptible species was lower than nonsusceptible (Production: susceptible $3.9( \pm 0.2) \mathrm{m}$, nonsusceptible $6.1( \pm 0.2) \mathrm{m}$, $N=887$; Restoration: susceptible $5.8( \pm 0.2) \mathrm{m}$, nonsusceptible 8.1 $( \pm 0.2) \mathrm{m}, N=1091$; both Mann-Whitney $U$ tests, $P<0.0001$ ). Canopy height was higher in Restoration than Production plots for each season (S00: Production $9.8( \pm 0.2) \mathrm{m}$, Restoration 13.9 $( \pm 0.2) \mathrm{m}, N=927$; W01: Production $11.3( \pm 0.1) \mathrm{m}$, Restoration $13.8( \pm 0.1) \mathrm{m}, N=1047$; both Mann-Whitney $U$ tests, $P<0.0001$ ).

Six bird species were captured in both management systems ( $>10$ captures in each). Only clay-colored robin prevalence differed significantly between the two management systems (Restoration: 22.7\%, Production: 6.9\%, $\chi^{2}=6.12, P=0.013$ ). All other species showed no significant difference in prevalence (Table 1). Using a Bonferroni approach to control for multiple testing, none of the species was significantly different (Bonferroni corrected $\alpha<0.0083$ ). 
BODY CONDITION.-Of the ten susceptible resident species with $>20$ captures including both infested and noninfested individuals, only orange-billed nightingale-thrush (Catharus aurantiirostris) $(P=0.0014)$ differed significantly in body condition index between infested and noninfested individuals after controlling for testing multiple species with Bonferroni correction $(\alpha<0.05$, Bonferroni corrected $\alpha<0.005$ ). The white-throated robin (Turdus assimilis) showed a marginal trend but was not significant with Bonferroni $(P$ $=0.043)$. Both species had a higher body condition index for noninfested individuals. None of the five susceptible migrant species showed a significant difference $(\alpha<0.05$, Bonferroni corrected $\alpha$ $<0.01$ ).

\section{DISCUSSION}

FORAGING BEHAVIOR.-My data support the hypothesis proposed by Literak et al. (2001) that prevalence rates for individual species depend on the length of individual exposure in an environment with active chigger larvae. Susceptible species (with $>5 \%$ prevalence) foraged more frequently in lower vegetation layers and had lower foraging heights than nonsusceptible species. In addition, higher prevalence for low foraging species indicates the importance of bird behavior in determining exposure risk. However, the relatively low coefficient of determination $\left(R^{2}=0.24\right)$ of this significant relationship also indicates that foraging behavior is not the only factor determining exposure risk, a number of low foraging species had zero or low prevalence. In particular, the rufous-breasted spinetail Synallaxis erythrothorax foraged at less than $1 \mathrm{~m}$, but had a prevalence of zero. These species may have additional behaviors (i.e., preening or dusting behavior) or other inherent (i.e., physiological or genetic) differences to avoid or control ectoparasite infestation. Notably, a number of warblers that forage low in the understory also had low prevalence (Nashville warbler Vermivora ruficapilla, magnolia warbler Dendroica magnolia, Wilson's warbler, and the resident rufous-capped warbler). Additional research is needed to identify how these species avoid or reduce infestation.

Seasonal differences in behavior may lead to differences in mite prevalence. During winter sampling, when infestation prevalence was highest, resident birds foraged more frequently in lower vegetative layers (Dietsch et al. 2007). The dramatic increase in mite prevalence during winter may be linked to shifts in foraging to lower vegetation layers. In follow-up research to this study, rufouscapped warblers foraged lower during the winter season (Jedlicka et al. 2006). Other behaviors may also vary seasonally to alter bird exposure to mite infestation (e.g., roost site, daytime resting location, or resting duration).

MANAGEMENT PRACTICES.-Birds captured in the Restoration plots showed a higher prevalence of mite infestation than did those netted at the more open Production sites. Prevalence was lower despite an apparent increased risk of exposure to mites as indicated by a lower mean foraging height in Production plots. This suggests that chigger larvae may be less abundant in the more open system. Susceptible species also foraged more frequently in lower vegetation layers in Production, particularly in the coffee layer. However, observations of birds foraging in the ground and herbaceous layers were a greater fraction of total observations in Restoration plots (13.1\%) than in Production plots $(8.7 \%)$. Additional sampling across a broader spectrum of coffee management practices on two additional farms in the region suggest that the results reported here are part of a larger pattern of declines in prevalence with increased management intensity (T. Dietsch, pers. obs.), but unequal sample effort and confounding factors related to temporal and habitat variation make direct comparisons problematic. A larger, better-controlled study is required to confirm this pattern.

This lower abundance of mites in the more-intensive management system is similar to the pattern of biodiversity loss with intensification of coffee management shown for other taxa in this system (Perfecto et al. 2003, Mas \& Dietsch 2004). Reduced humidity or differences in soil or leaf litter processes may impose life-history constraints that help regulate chigger populations. Low humidity has been shown to reduce ectoparasite pressure (Moyer et al. 2002), though larvae attached and feeding on bird fluids may not face the same pressures. Interestingly, this is contrary to observed seasonal differences of higher mite prevalence during the drier winter sampling period (Dietsch 2005a). Habitat-specific differences in other behaviors may change exposure risk. There may also be more sites available in the more-intensive management system for grooming behaviors, such as dust bathing locations, which help to control ectoparasite loads (Hendricks \& Hendricks 1995).

BODY CONDITION.- I did not test fitness and physiological effects directly. However, body weight corrected for body size is an established measure of fitness (Rogers \& Odum 1964, Slagsvold 1982). Ectoparasites have been shown to reduce host fitness and body condition (Brown et al. 1995). In this study, some evidence of reduced body condition was found for infested individuals in two of 15 species tested, though only the orange-billed nightingalethrush differed significantly when corrected to eliminate effects of multiple testing. Body condition is dependent both on resource availability and physiological stress. Consequently, if resource availability were sufficient to overcome losses to ectoparasites and to meet other energetic requirements, body condition would not necessarily reflect infestation status. Though effects on adult fitness may be minimal, chigger mite larvae could still reduce reproductive success. Clayton and Tompkins (1995) found a similar lack of effect on adult body condition from mesostigmatid mites that contrasted with dramatic reductions in hatching success, primarily from reduced incubation due to agitation from the mites. A more comprehensive or focused study is needed to determine if chiggers have stronger fitness costs during reproduction or other periods of energetic stress. Nonetheless, there is some evidence that studies evaluating fitness or body condition could benefit from collecting information on ectoparasite infestation intensity as a potential confounding factor.

Chigger larvae infestations of birds and mammals have been described as sporadic and localized (Loomis 1978). While I found significant temporal variation between seasons and years, chigger larvae were present at high levels on many species throughout the two years of the study. Mites have been found on three coffee farms 
in this region indicating that, at a minimum, this is a regional phenomenon within the Soconusco district of Chiapas, Mexico ( $\mathrm{T}$. Dietsch, pers. obs.). Nonetheless, this study took place within two coffee shade management systems on one farm in Chiapas, Mexico. Consequently, though similar mite larvae were observed across the region and by other researchers in other parts of Central America, there may be site-specific effects that limit whether the patterns I report here are generalizable. Also, chigger larvae were not collected concurrently with this study. The larvae collected and identified at the same study site following the completion of this work indicate that the mite infestation observed in this study was probably from multiple species (see Table 4 in Dietsch 2005a). Differences between chigger species may account for some of the variation that was observed during the course of this work. Nonetheless, this study provides insight into the ecological relationship between avian hosts and this widespread ectoparasite, many species of which are host generalists.

The ecology of ectoparasites and their relation to birds merit further study, including their geographic distributions and the degree to which they are affected by land management decisions. Further research could help determine patterns of infestation for migratory birds and whether long-distance movements by birds are an important component of the ecology of chigger mite communities. A few species of chigger (Trombiculidae and Leeuwenhoekiidae) have been identified as vectors for human and wildlife pathogens (Wharton \& Fuller 1952, Proctor \& Owens 2000). Given that migratory birds can travel considerable distances in the time necessary for larvae to engorge themselves and detach, monitoring programs for ectoparasites may be important for recognizing the causes and spread of emerging diseases.

\section{ACKNOWLEDGMENTS}

I thank G. Ibarra-Núñez, I. Perfecto, T. Root, J. Vandermeer, R. Greenberg, E. Silverman, and my fellow graduate students for support and helpful feedback on this research. A project such as this would not have been possible without the enthusiastic contributions of a team of field assistants: B. Ramirez Lopez, M. Agudelo Arango, R. Danner, M. Grosselet, S. Langridge, J. Lynn, and I. Samuels. J. Luis Rangel, P. Bichier, A. Garcia-Ballinas and G. Lopez Bautista provided important technical assistance. J. L. Rangel also assisted in translating the abstract to Spanish. W. Peters, owner of Finca Irlanda, generously allowed us access to the field site. Special thanks to B. O'Conner at the University of Michigan Museum of Zoology for information on chigger ecology. A. Hoffman, J. B. Morales-Malacara, and Biol. G. Montiel Parra from Autonomous National University of Mexico provided invaluable assistance with specimen preparation and identification of chigger larvae. Funding was provided by the Latin American and Caribbean Studies Department, School of Natural Resources and Environment, and the Rackham Graduate School of the University of Michigan; Kalamazoo Audubon Society; Chicago Zoological Society; Sigma Xi; and the National Science Foundation grant \# CEB-9981526.

\section{LITERATURE CITED}

Baker, E. W., T. M. Evans, D. J. Gould, W. B. Hull, and H. L. Keegan. 1956. A manual of parasitic mites of medical or economic importance. National Pest Control Association, Inc., New York, New York.

Booth, D. T., D. H. ClaYTON, AND B. A. BlOCK. 1993. Experimental demonstration of the energetic cost of parasitism in free-ranging hosts. Proc. $\mathrm{R}$. Soc. Lond. B 253: 125-129.

Brown, C. R., M. B. Brown, AND B. Rannala. 1995. Ectoparasites reduce long-term survival of their avian host. Proc. R Soc. Lond. B 262: 313319.

Bush, A. O., K. D. Lafferty, J. M. Lotz, And A. W. Shostak. 1997. Parasitology meets ecology on its own terms: Margolis et al. revisited. J. Parasitol. 83: 575-583.

Clayton, D. H. And D. M. TompKins. 1995. Comparative effects of mites and lice on the reproductive success of rock doves (Columba livia). Parasitology 110: 195-206.

Clayton, D. H., and B. A. Walther. 1997. Collection and quantification of arthropod parasites of birds. In D. H. Clayton and J. Moore (Eds.). Host-parasite evolution: General principles and avian models. pp. 419440. Oxford University Press, Oxford, UK.

DiETsCH, T. V. 2003. Conservation and ecology of birds in coffee agroecosystems of Chiapas, Mexico. PhD Dissertation, University of Michigan, School of Natural Resources \& Environment, Ann Arbor, Michigan.

DieTSCH, T. V. 2005a. Seasonal variation of infestation by ectoparasitic chigger mite larvae (Acarina: Trombiculidae) on resident and migratory birds in coffee agroecosystems of Chiapas, Mexico. J. Parasitol. 91: 1294-1303.

DieTsCH, T. V. 2005b. Comparing infestation rates of chigger mite larvae (Acarina: Trombiculidae) on resident and migratory birds in Chiapas, Mexico illustrating a rapid visual assessment protocol. In C. J. Ralph and T. D. Rich (Eds.). Bird conservation implementation and integration in the Americas, pp. 1129-1137. Proceedings of the Third International Partners in Flight Conference. 2002 March 20-24; Asilomar, California; Volume 2. Gen. Technical Report PSW-GTR-191. Pacific Southwest Research Station, Forest Service, U.S. Department of Agriculture, Albany, California.

Dietsch, T. V., I. Perfecto, ANd R. Greenberg. 2007. Avian foraging behavior in two coffee agroecosystems of Chiapas, Mexico. Biotropica 39: 232240.

DufFY, D. C. 1983. Tick parasitism on densely nesting Peruvian seabirds. Ecology 64: 110-119.

EwING, H. E. 1944. The trombiculid mites (chigger mites) and their relation to disease. J. Parisitol. 30: 339-365.

Greenberg, R., V. Pravosudov, J. Sterling, A. Kozlenko, and V. KontorSHIKOV. 1999. Divergence in foraging behavior of foliage-gleaning birds. Oecologia 120: 451-462.

HENDRICKS, P., AND L. N. HeNDRICKS. 1995. Behavior and interaction of Bewick's and House Wrens at a common dusting site with comments on the utility of dusting. J. Field Ornithol. 66: 492-496.

Jedlicka, J., R. Greenberg, I. Perfecto, S. Philpott, and T. Dietsch. 2006. Seasonal foraging niche shifts of tropical avian residents: resource competition at work? J. Trop. Ecol. 22: 385-395.

Literak I, M. Honza, B. PinOwsKa, and A. Haman. 2001. Larvae of Trombiculid mites (Acarina: Trombiculidae) in wild bird in Slovak and Polish Carpathians. Acta Vet. Brno 70: 479-483.

LoOMIS, E. C. 1978. External parasites. In M. S. Hofstad (Ed.). Diseases of poultry, pp. 667-704. Iowa State University Press, Ames, Iowa.

MANLY, B. F. J. 2001. Statistics for environmental science and management. Chapman \& Hall/CRC, Boca Raton, Florida.

Margolis, L., G. W. Esch, J. C. Holmes, A. M. Kuris, and G. A. Schad. 1982. The use of ecological terms in parasitology. J. Parasitol. 68: 131133.

MartineZ, E., AND W, Peters. 1996. La cafeticultura biológica: la finca Irlanda como estudio de caso de un deseño agricoecológico. In J. T. Arriaga, F. L. González, R. C. Arózqueta, and P. T. Lima (Eds.). Ecología aplicada 
a la agricultura: Temas selectos de México. Universidad Autónomo Metropolitana, Unidad Xochimilco, DF, México, pp. 159-183.

Mas, A. H., AND T. V. DieTSCH. 2004. Linking shade coffee certification programs to biodiversity conservation: Butterflies and birds in Chiapas, Mexico. Ecol. Appl. 14: 642-654.

Moguel, P., AND V. M. TolEDO. 1999. Biodiversity conservation in traditional coffee systems in Mexico. Conserv. Biol. 12: 1-11.

MoYer, B. R., A. J. PACEJKA, AND D. H. ClaYTON. 2002. Low humidity reduces ectoparasite pressure: Implications for host life history evolution. Oikos 97: 223-228.

Perfecto, I., A. Mas, T. Dietsch, and J. Vandermeer. 2003. Conservation of biodiversity in coffee agroecosystems: A tri-taxa comparison in southern Mexico. Biodivers. Conserv. 12: 1239-1252.

Proctor, H., AND I. Owens. 2000. Mites and birds: Diversity, parasitism and coevolution. Trends Ecol. Evol. 15: 358-364.
Pruett-Jones, M., AND S. PruetT-Jones. 1991. Analysis and ecological correlates of tick burdens in a New Guinea avifauna. In J. E. Loye and M. Zuk (Eds.). Bird-parasite interactions: Ecology, evolution, and behaviour. pp. 154-176. Oxford University Press, Oxford, UK.

PyLE, P. 1997. Identification guide to North American Birds, Part 1, Columbidae to Ploceidae. Slate Creek Press, Bolinas, California.

Rogers, D. T., AND E. P. Odum. 1964. Effect of age, sex and level of fat deposition on major body components in some wood warblers. Auk 81: 505-513.

Slagsvold, T. 1982. Criteria for estimating the condition of birdsrelationship between fat content and body size dimensions in the Hooded Crow Corvus corone cornix. Ornis Scandinavica 13: 141144.

Wharton, G. W, And H. S. Fuller. 1952. A manual of the chiggers. Mem. Entomol. Soc. Wash., No. 4, Washington, DC. 